\title{
Imaging Review of New and Emerging Sinonasal Tumors and Tumor-Like Entities from the Fourth Edition of the World Health Organization Classification of Head and Neck Tumors
}

\author{
(D) K.E. Dean, DD. Shatzkes, and (D)C.D. Phillips
}

\begin{abstract}
SUMMARY: The sinonasal tract is an environment diverse with neoplasia. Given the continued discovery of entities generally specific to the sinonasal tract, the fourth edition of the World Health Organization Classification of Head and Neck Tumors was released in 2017. It describes 3 new, well-defined entities and several less-defined, emerging entities. The new entities are seromucinous hamartomas, nuclear protein in testis carcinomas, and biphenotypic sinonasal sarcomas. Emerging entities include human papillomavirus-related sinonasal carcinomas, SWI/SNF-related matrix-associated actin-dependent regulator of chromatin subfamily B member 1-deficient sinonasal carcinomas, renal cell-like adenocarcinomas, and chondromesenchymal hamartomas. The literature thus far largely focuses on the pathology of these entities. Our goal in this report was to familiarize radiologists with these new diagnoses and to provide available information regarding their imaging appearances.
\end{abstract}

ABBREVIATIONS: HPV = human papillomavirus; NUT = nuclear protein in testis; NMC = nuclear protein in testis midline carcinomas; SCC = squamous cell
carcinoma; $\mathrm{SH}=$ seromucinous hamartoma; $\mathrm{SWI} / \mathrm{SNF}=\mathrm{SWItch} /$ Sucrose Non-Fermentable; SMARCB1 = SWI/SNF-related matrix-associated actin-dependent regu-
lator of chromatin subfamily B member $\mathrm{l} ; \mathrm{SNUC}=$ sinonasal undifferentiated carcinoma; $\mathrm{REAH}=$ respiratory epithelial adenomatoid hamartoma; WHO = World Health
Organization

$\mathbf{T}$ he complex anatomy and histology, numerous potential carcinogenic exposures, and vast cancer genomics cause the aerodigestive tract to be affected by a diverse range of tumors and tumor-like entities. To stay current, the classification of head and neck tumors is frequently redefined. The fourth edition of the World Health Organization Classification of Head and Neck Tumors, released in 2017, includes 3 new, well-defined entities and several less-defined, emerging entities within the sinonasal tract. The emerging entities are provisional diagnoses or are only described in the context of differential diagnoses. ${ }^{1,2}$

The new sinonasal entities are seromucinous hamartomas, nuclear protein in testis (NUT) carcinomas, and biphenotypic sinonasal sarcomas. Emerging entities include SWI/SNF-related matrix-associated actin-dependent regulator of chromatin subfamily B member 1 (SMARCB1)-deficient sinonasal carcinomas, renal cell-like adenocarcinomas, and chondromesenchymal

Received October 26, 2018; accepted after revision December 20.

From the Department of Radiology (K.E.D., C.D.P.), NewYork-Presbyterian/Weill Cornell Medical Center, New York, New York; and Department of Radiology (D.S.), Lenox Hill Hospital, Northwell Health, New York, New York.

Please address correspondence to Kathryn E. Dean, NewYork-Presbyterian/Weill Cornell Medical Center, Department of Radiology, 525 E 68th St, New York, NY 10065; e-mail: ked9042@med.cornell.edu; @kateedean

-- Indicates open access to non-subscribers at www.ajnr.org

三 Indicates article with supplemental on-line table.

http://dx.doi.org/10.3174/ajnr.A5978

hamartomas. Human papillomavirus (HPV)-related sinonasal carcinoma with adenoid cystic features is described as an emerging entity within the World Health Organization (WHO) update. A subsequently published, expanded series suggests that this entity may be a distinct one, termed "HPV-related multiphenotypic sinonasal carcinoma." 3

To date, the literature regarding these updates largely concerns the histopathologic features. ${ }^{2,4,5}$ A radiologist may see these rare entities reported as pathologic diagnoses, and some familiarity with the nomenclature, pathology, and imaging features is important. This article aims to briefly review the histopathologic classifications of sinonasal tumors as well as provide imaging examples and reported imaging characteristics of these new and emerging entities. While there are no true pathognomonic imaging features and biopsy remains the criterion standard, there are findings that may be useful to characterize these lesions.

\section{REVIEW OF HISTOLOGIC TYPES OF SINONASAL TUMORS}

Accurate interpretation of sinonasal tumor imaging by neuroradiologists necessitates a fundamental understanding of the histologic subtypes. Basic classification groups include squamous cell carcinomas (SCCs), adenocarcinomas, sarcomatous/mesenchymal tumors, neuroectodermal tumors, salivary neoplasms, papillomas, respiratory epithelial lesions, hematolymphoid tumors, and tumor-like entities (On-line Table). 


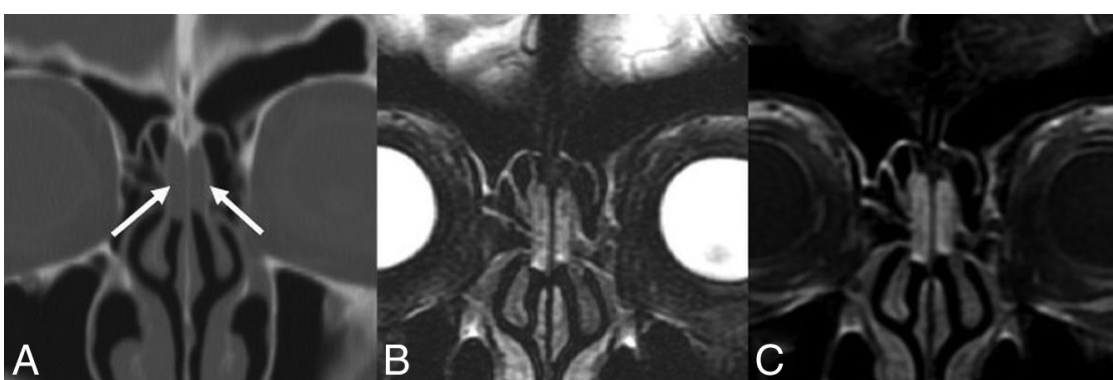

FIG 1. REAH. A, Coronal noncontrast CT shows mildly expansile soft tissue in the bilateral olfactory clefts without adjacent bony erosion or destruction (white arrows). Coronal T2 fat-saturated $(B)$ and coronal $T 1$ postcontrast, fat-saturated $(C)$ MR images in the same patient show the lesions to be heterogeneous and hyperintense to the cortex on T2WI and enhancing.

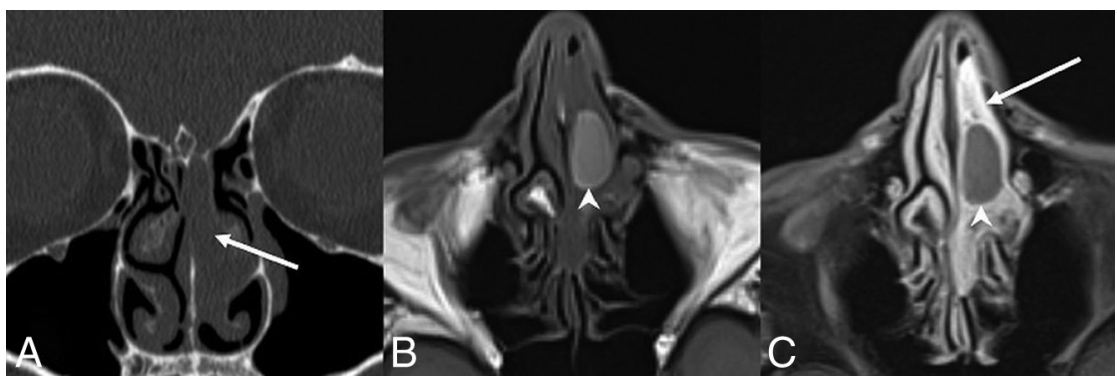

FIG 2. SH. A, Coronal noncontrast CT shows expansile soft tissue in the left olfactory recess extending inferiorly into the superior nasal cavity (white arrows) without erosive or destructive bony changes, similar to an REAH. Axial T1 precontrast $(B)$ and axial $T 7$ postcontrast, fat-saturated (C) images demonstrate predominantly homogeneous enhancement. The relatively hyperintense, nonenhancing central component on TIWI suggests proteinaceous content (white arrowheads), possibly reflecting glandular secretions. Areas of relative central hyperintense signal on precontrast TIWI are not described in other published examples.

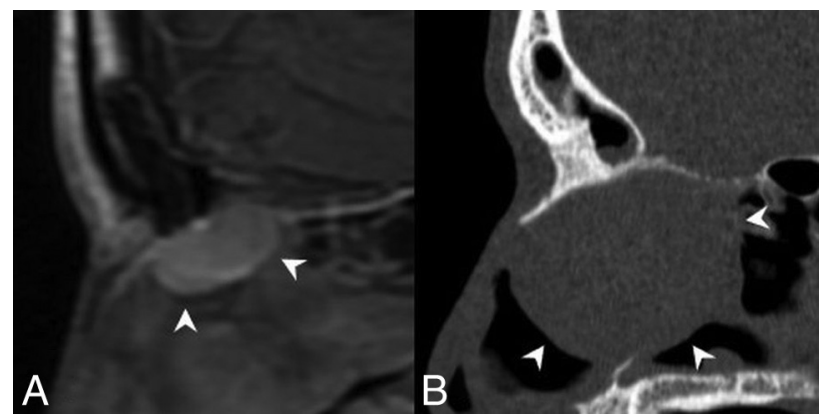

FIG 3. Crescent sign. $A$, Sagittal Tl postcontrast MR image of an REAH. $B$, Sagittal noncontrast $C T$ image of a seromucinous hamartoma demonstrates a characteristic half-moon morphology (white arrowheads), which we have termed a "crescent sign" when the lesions arise in the olfactory recess.

Squamous cell carcinomas are defined as keratinizing and nonkeratinizing subtypes. ${ }^{6}$ Nonkeratinizing SCCs account for about $15 \%-20 \%$ of sinonasal SCCs. ${ }^{4}$ Under the umbrella of nonkeratinizing SCC is the emerging subgroup of HPV-related sinonasal carcinoma. ${ }^{1,7}$

Sinonasal adenocarcinomas are classified as either intestinal or nonintestinal subtypes. ${ }^{8}$ Nonintestinal types are either high- or low-grade. ${ }^{9,10}$ Emerging within the subgroup of low-grade nonintestinal is one that resembles conventional clear cell adenocarcinoma, thus termed "renal cell-like adenocarcinoma."

Other histologic carcinoma groups include neuroendocrine tumor, lymphoepithelial carcinoma, sinonasal undiffer- entiated carcinoma (SNUC) including the emerging subtype of SMARCB1deficient sinonasal carcinoma, and the newly defined NUT carcinoma. ${ }^{1,2,11}$ Biphenotypic sinonasal sarcoma is a newly defined sinonasal sarcomatous/ mesenchymal tumor. New tumorlike entities include seromucinous hamartomas and chondromesenchymal hamartomas. ${ }^{1}$

\section{NEW ENTITIES \\ Seromucinous Hamartoma}

Clinical and Histopathologic Review. Sinonasal epithelial hamartomas are benign lesions that contain components of normal ciliated respiratory epithelium. Subtypes include respiratory epithelial adenomatoid hamartoma (REAH) and the newly defined seromucinous hamartoma (SH). ${ }^{12-15} \mathrm{SH}$ has increased seromucinous glandular components compared with REAH, akin to adenosis. $^{16}$

Both lesions affect adults with a male predilection, 7:1 for REAH and 5:2 for SH. Presenting symptoms for both include nasal congestion, anosmia, and rhinorrhea. ${ }^{15,17}$ REAHs have been described in isolation and in the setting of concomitant sinonasal disease from inflammatory polyposis to malignancy, an association that suggests a potential reactive etiology of these lesions. ${ }^{18,19}$ Recurrence of REAHs and SHs after resection is rare. ${ }^{16}$

Imaging Features. Just as there is histologic overlap of REAH and $\mathrm{SH}$, their imaging features are similar. REAHs classically arise in the olfactory clefts. Other described sites for both lesions include the nasal septum, middle turbinate, and uncinate process. The lesions may be bilateral. ${ }^{16,17,20}$

REAHs are well-defined, near muscle density, and homogeneous on CT. The olfactory cleft is often expanded and smoothly remodeled without erosive changes. ${ }^{18}$ REAHs are heterogeneous on T2WI and isointense on T1WI relative to the cortex and enhance uniformly (Fig 1). ${ }^{21}$ To our knowledge, no substantial dedicated literature regarding the appearance of SHs on imaging exists to date. Published CT images in the pathology literature show an appearance similar to that of REAH. ${ }^{20} \mathrm{MR}$ images of a proved SH published here show similar signal on T2WI and enhancement patterns (Fig 2). On the sagittal images, both often have a characteristic half-moon appearance when situated in the olfactory cleft, here described as a "crescent sign" (Fig 3).

Diagnostic Tips and Differentials. Differentiating REAH from SH is not possible by imaging alone. The presence of frank bony erosion or skull base defects would favor encephalocele, carcinoma, or esthesioneuroblastoma (other soft-tissue lesions typical of the olfactory cleft) over $\mathrm{REAH}, \mathrm{SH}$, or benign inflammatory polyp. ${ }^{22}$ The 


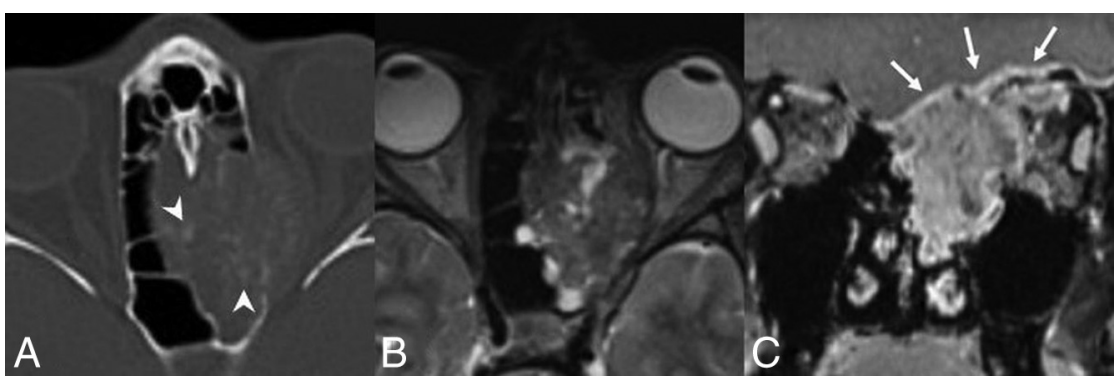

FIG 4. NUT carcinoma. A, Axial noncontrast CT image shows a locally destructive mass centered within the left ethmoid sinus extending into the left orbit and laterally displacing the medial rectus muscle. There is faint mineralization within the mass (white arrowheads). Axial T2 fatsaturated $(B)$ and coronal $T 1$ postcontrast, fat-saturated $(C)$ MR images from the same patient show the mass to be heterogeneous but predominantly hypointense to the cortex on T2WI and avidly enhancing. The mass extends into the anterior cranial fossa with dural involvement (white arrows). Images are courtesy of Dr Nafi Aygun, Johns Hopkins Hospital.

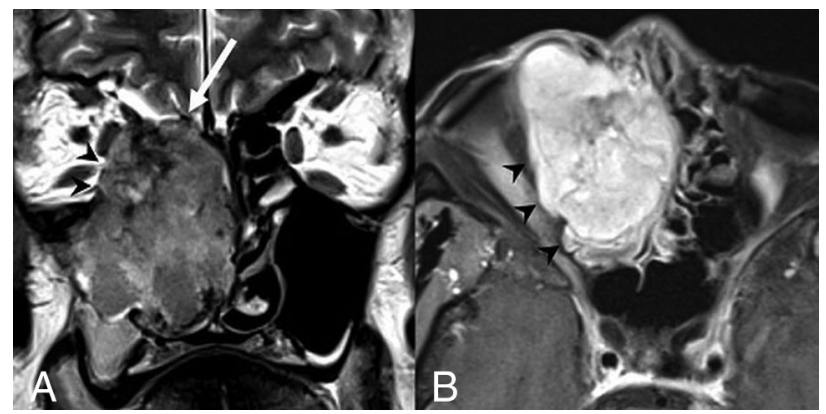

FIG 5. Biphenotypic sinonasal sarcoma. Coronal $T 2(A)$ and axial $T 1$ postcontrast, fat-saturated $(B)$ MR images show a well-marginated but locally aggressive right nasoethmoid mass involving the right maxillary sinus. The mass extends through the right lamina papyracea to involve the right orbit (black arrowheads) and through the right lateral lamella and fovea ethmoidalis into the right anterior cranial fossa (white arrow). Heterogeneous but predominantly isointense signal relative to the cortex on T2WI and avid contrast enhancement are noted.

"crescent sign" morphology on sagittal images, in our experience, is suggestive of REAH and SH within the olfactory cleft.

\section{NUT Carcinoma}

Clinical and Histopathologic Review. Nuclear protein in testis midline carcinomas (NMCs) were initially described in the mediastinum and more recently in the sinonasal cavity. Although there are $<100$ cases reported, the clear genomics and histology allow the sinonasal NMCs to be included as a new entity in the latest WHO release. ${ }^{23-25}$ NMCs show undifferentiated round blue cells growing in the submucosa abruptly juxtaposed to mature keratinizing squamous cells. ${ }^{26,27}$ The diagnosis requires identification of the NUTM1 gene rearrangement, often with BRD4. ${ }^{28}$

Sinonasal nuclear protein in testis midline carcinoma is highly aggressive and infiltrative, with a poor prognosis and a median progression-free survival of 6.6 months and an overall median survival of 9.7 months. ${ }^{29}$ Presenting symptoms include nasal obstruction, epistaxis, and orbital pain with a wide age range at presentation and a slight female predominance. ${ }^{25,30}$

Imaging Features. While no substantial literature regarding imaging of sinonasal NMCs exists, case reports and images here published show aggressive features similar to those within the chest, where there is often airway and vascular invasion. ${ }^{31}$ In the sinonasal cavity, rapid growth and infiltration may result in orbital or cranial involvement. Nearly half have regional or distant metastases at presentation. ${ }^{25,27,32}$

On CT, the mass is near muscle density. Bony hyperostosis is described. ${ }^{31,32}$ In the case published here, there are internal mineralizations but no dystrophic calcifications as seen in thoracic NMCs. ${ }^{31}$ On MR imaging, the tumors are hypointense on T1WI and heterogeneous on T2WI relative to the cortex and enhancing (Fig 4). ${ }^{33}$ Published cases are FDG-avid. ${ }^{34}$

Diagnostic Tips and Differentials. The locally aggressive imaging characteristics of sinonasal NMCs are almost entirely nonspecific, with a multitude of potential differentials, including other carcinomas, lymphomas, and sarcomas. PET/CT may play an important role in staging, given the propensity for distant metastases at presentation. $^{33}$

\section{Biphenotypic Sinonasal Sarcoma}

Clinical and Histopathologic Review. Biphenotypic sinonasal sarcomas are histologically similar to cellular schwannomas or malignant peripheral nerve sheath tumors, with infiltrating spindle cells and entrapped invaginations of normal sinonasal epithelium. ${ }^{34-36}$ Diagnosis requires the rearrangement of the PAX3 gene, often with MAML3. ${ }^{35,37,38}$

With about 50 reported cases, there is a suggested female predominance (2-3:1), often occurring in the sixth decade. ${ }^{2,35}$ Described throughout the sinonasal tract, the most common locations of tumors include the superior nasal cavity and ethmoid sinuses, and they present with facial pressure and nasal obstruction. ${ }^{40}$ The tumors are slow growing with no published cases with metastases to date. Local recurrence, however, is reported in about half of the cases. ${ }^{35,39}$

Imaging Features. The masses are well-marginated but locally aggressive and can erode through the skull base or into the orbit. Associated hyperostotic bone formation is described on CT. ${ }^{35,40}$ The masses avidly enhance and are isointense-to-hypointense to the cortex on T2WI (Fig 5).

Diagnostic Tips and Differentials. Exceedingly rare with nonspecific imaging findings, biphenotypic sinonasal sarcomas have imaging findings similar to those of many other primary sinonasal carcinomas and sarcomas. Hyperostotic bone formation is described in several of the published cases but is again nonspecific. ${ }^{35}$

\section{EMERGING ENTITIES: PROVISIONAL \& DIFFERENTIAL DIAGNOSES HPV-Related Sinonasal Carcinoma}

Clinical and Histopathologic Review. The sinonasal cavity is a common location within the aerodigestive tract for HPV-related carcinomas. Twenty-to-thirty percent of sinonasal carcinomas 


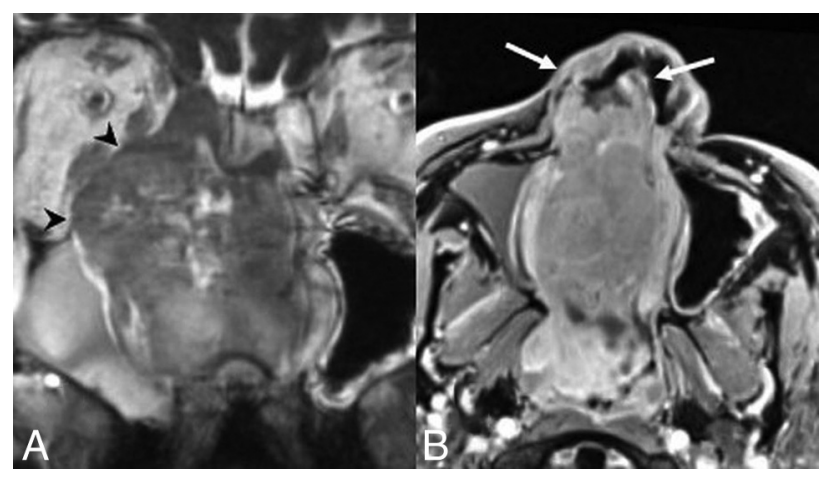

FIG 6. HPV-related sinonasal carcinoma, a nonmultiphenotypic variant. Coronal T2 $(A)$ and axial T1 postcontrast, fat-saturated $(B)$ MR images show a right nasoethmoid mass with extension to the right maxillary sinus and orbit (black arrowheads) as well as the left nasal cavity. There is anterior extension into the right nasal vestibule (white arrows). The mass demonstrates heterogeneous hyperintensity relative to the cortex on T2WI and avidly enhances. Images are courtesy of Dr Nafi Aygun, Johns Hopkins Hospital.

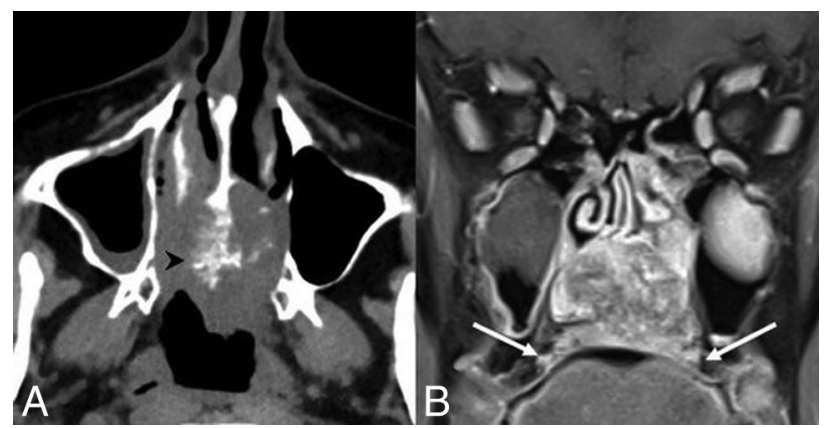

FIG 7. HPV-related multiphenotypic sinonasal carcinoma. Axial noncontrast $C T(A)$ and coronal T1 postcontrast, fat-saturated $(B) M R$ images show an aggressive mass centered in the inferior nasal cavity. The mass is isodense to muscle with an aggressive periosteal reaction along the nasal septum (black arrowhead). The mass is enhancing and locally destructive, invading the marrow of the hard palate (white arrows).

have associated high-risk HPV subtypes. ${ }^{2,7,41}$ Sinonasal HPVrelated carcinoma remains an emerging entity because the histopathology is less clear and no definitive prognostic benefit to HPV association is known as in the oropharynx. Preliminary evidence is at least suggestive of improved disease-free and overall survival. ${ }^{7,41,42}$

There are several known HPV-related sinonasal carcinoma variants (squamous, papillary, small-cell, adenosquamous, basaloid). One particular variant is only described in the sinonasal tract: HPV-related multiphenotypic sinonasal carcinoma. ${ }^{3,7}$ At the time of the WHO update publication, this variant was called HPV-related carcinoma with adenoid cystic-like features, given the associated microcystic pseudoductal spaces. It was a provisional entity with only 9 documented cases. ${ }^{7}$ A recent expanded series of 49 cases describes a more complex histopathology with multiple subphenotypes and proposes a change from a provisional diagnosis to a distinct entity renamed "HPV-related multiphenotypic sinonasal carcinoma." 3

Arising in adults, the multiphenotypic variant commonly presents with nasal congestion and epistaxis. Around $90 \%$ of the documented cases originate in the nasal cavity. Distant metastases are described in 2 patients, 1 to the lung and 1 to a finger. Approximately $25 \%$ have local recurrence. ${ }^{43}$

Imaging Features. Little is published on the imaging findings of HPV-related sinonasal carcinomas as a group. Pathology-proved cases here published are similar to those of other sinonasal SCCs destroying, remodeling, and/or invading bone. They have variable signal relative to the cortex on T2WI and enhance on MR imaging (Figs 6 and 7). The multiphenotypic variant case shown here was FDG-avid.

Perineural tumor spread is uncommon in the multiphenotypic variant, unlike true adenoid cystic carcinoma. ${ }^{2,3}$ No cystic nodal metastases have yet been described. ${ }^{43}$

Diagnostic Tips and Differentials. HPV-related sinonasal carcinoma variants, including the multiphenotypic type, share many imaging characteristics with one another and with other primary sinonasal carcinomas (SCC, adenocarcinoma, and so forth). Cystic nodal metastases common in HPV-related carcinomas elsewhere in the aerodigestive tract and perineural spread common to true adenoid cystic carcinomas have not yet been described. ${ }^{2,3,43}$

\section{SMARCB1-Deficient Sinonasal Carcinoma}

Clinical and Histopathologic Review. SMARCB1-deficient sinonasal carcinomas are composed of mitotically active epithelioid nests with basaloid features and necrosis similar to SNUC and nonkeratinizing SCC. ${ }^{44-46}$ Given this histologic overlap, SMARCB1-deficient sinonasal carcinomas may represent a distinct entity or a histologic pattern seen in various other tumors. ${ }^{11,47}$ Diagnosis is by immunohistochemical analysis demonstrating complete loss of SMARCB1 expression, a tumor-suppressor gene implicated in several tumors with rhabdoid features. ${ }^{44,45,47,48}$ SMARCB1-deficient sinonasal carcinoma is an emerging entity currently classified as a SNUC subtype.

SMARCB1-deficient sinonasal carcinomas are more common in women, with a wide age range from young adult to elderly. ${ }^{11,48}$ Local recurrence is common. Frequently with local or distant metastases at diagnosis, approximately $40 \%$ of cases are lethal. ${ }^{2}$

Imaging Features. In an imaging analysis of 17 cases, 8 were centered within the nasoethmoid region. ${ }^{49}$ The tumors are highly aggressive and infiltrative, many demonstrating local skull/brain invasion. Eight cases had dural involvement, with extension through the dura in 3 cases. ${ }^{49}$

On CT, the tumors are isodense to muscle, with calcifications in half of the reported cases. Both expansile and erosive patterns of bony involvement along the skull base are described with a "hair on end" pattern of periosteal reaction in several cases. ${ }^{49} \mathrm{On} \mathrm{MR}$ imaging, most lesions are isointense on T1WI and variable on T2WI relative to the cortex, predominantly avidly enhancing with moderately restricted diffusion (Fig 8). ${ }^{49}$ All cases were FDG-avid. ${ }^{49}$

Diagnostic Tips and Differentials. Within the broad differential for locally aggressive sinonasal tumors, including SNUC and other carcinomas, SMARCB1-deficient sinonasal carcinoma di- 


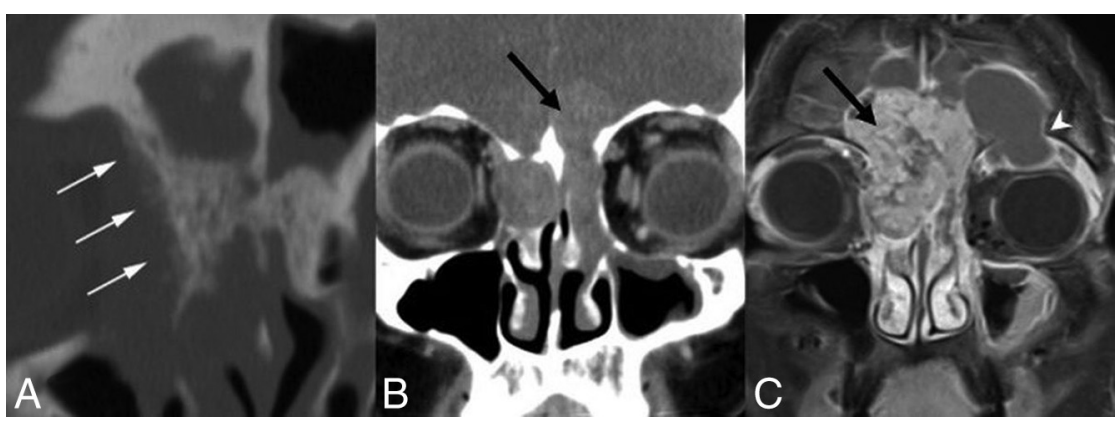

FIG 8. SMARCBI-deficient sinonasal carcinoma. A, Coronal noncontrast CT shows the "hair on end" pattern of calcification/periosteal reaction (white arrows) described in several published cases. Coronal postcontrast CT $(B)$ and coronal Tl postcontrast, fat-saturated $(C)$ MR images in a second patient demonstrate an enhancing nasoethmoid mass eroding the floor of the anterior cranial fossa (black arrows). There is also erosion of the right lamina papyracea with extraconal orbital extension. A secondary mucocele extends through the left orbital roof (white arrowhead).

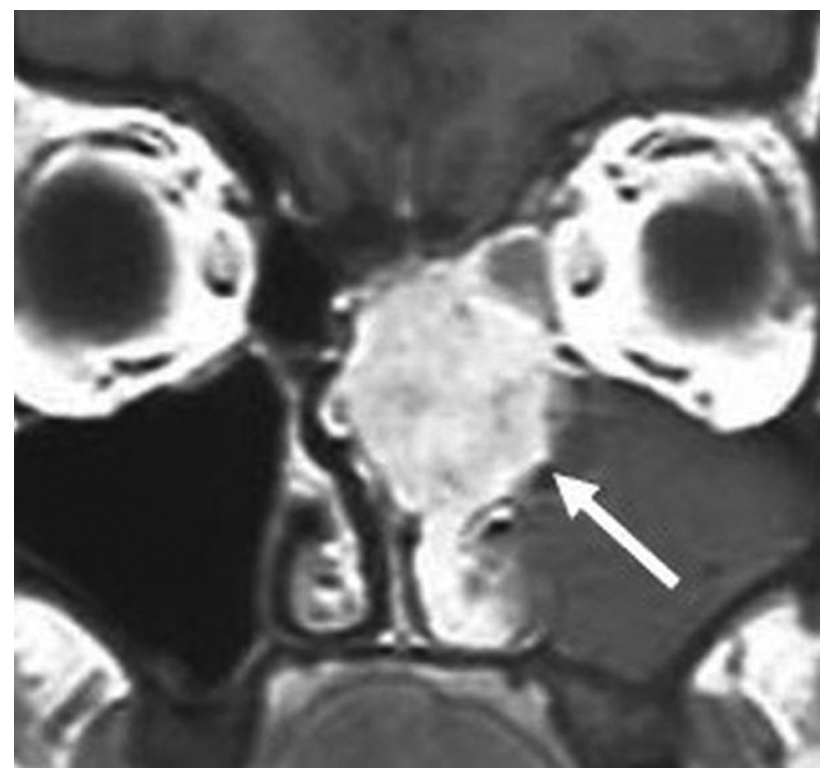

FIG 9. Renal cell-like adenocarcinoma. Coronal Tl postcontrast MR image shows an avidly enhancing, locally destructive, left nasoethmoid mass. The pronounced enhancement is akin to that of a renal cell carcinoma metastasis (white arrow). Images are courtesy of $\mathrm{Dr}$ Margie Brandwein, Mount Sinai Hospital.

agnosis is dependent on tissue sampling. Calcifications are a commonly found imaging feature.

\section{Renal Cell-Like Adenocarcinoma}

Clinical and Histopathologic Review. Renal cell-like adenocarcinoma is a variant of low-grade nonintestinal sinonasal adenocarcinoma with uniform cuboidal/columnar cells with glycogen-rich cytoplasm, akin to clear-cell renal cell carcinoma., ${ }^{4,50}$ With approximately 16 reported cases, it is an emerging entity in the latest WHO edition. The key differential diagnosis is renal cell carcinoma metastasis. In fact, the most common carcinoma to metastasize to the sinonasal tract is renal cell carcinoma. ${ }^{51}$ The distinguishing features are immunohistochemical, with renal cell-like adenocarcinoma negative for $P A X 8$, a renal cell carcinoma marker, and vimentin. ${ }^{4,51,52}$

Renal cell-like adenocarcinoma commonly presents with epi- staxis, with ages ranging from early adulthood to elderly and a female predominance (11:5). ${ }^{51,53}$ The tumor demonstrates indolent growth, and no local recurrence has yet been described. ${ }^{51}$

Imaging Features. Published cases show expansile, locally destructive masses with intracranial extension and dural involvement described. On MR imaging, the tumors are heterogeneous to the cortex on T2WI and enhance avidly, similar to renal cell carcinoma. ${ }^{54-56}$ A key diagnostic criterion is the lack of a concomitant suspicious renal mass (Fig 9).

Diagnostic Tips and Differentials. There are no pathognomonic imaging findings, and the differential is broad, including other aggressive primary and secondary lesions. The absence of a concomitant renal mass is key to diagnosing renal cell-like adenocarcinoma when tissue sampling is suggestive.

\section{Chondromesenchymal Hamartoma}

Clinical and Histopathologic Review. Chondromesenchymal hamartoma is an emerging tumor-like entity in children. There is a link to germline or somatic DICER1 gene mutations, which are also associated with pleuropulmonary blastoma tumor predisposition disorder. ${ }^{57}$ Histology demonstrates nodules of hyaline cartilage within the stromal components of spindle cells. ${ }^{58,59}$

The tumor is benign but locally aggressive, involving the paranasal sinuses, nasal cavities, and orbits. It is more common in male children with a mean age of 9 years. Nine of 42 cases in 1 series had local recurrence. One documented case had malignant transformation. ${ }^{59}$

Imaging Features. The masses are smoothly marginated and expansile, commonly with cystic components and calcifications on CT. Erosion of the skull base is often demonstrated. Half of the cases have internal calcifications. On MR imaging, solid components strongly enhance (Fig 10). ${ }^{60,61}$

Diagnostic Tips and Differentials. Overlapping imaging findings with other expansile benign-appearing pathology make chondromesenchymal hamartoma a histologic diagnosis but it should be considered in a mixed cystic and calcified sinonasal mass in a child.

\section{CONCLUSIONS}

The fourth edition of the World Health Organization Classification of Head and Neck Tumors defines several new well-defined and other emerging sinonasal tumor and tumor-like entities. While some of these lesions, including NMCs, biphenotypic sinonasal sarcomas, HPV-related multiphenotypic sinonasal carcinomas, and seromucinous hamartomas, are considered distinct, many others lack clearly defined histopathology and genomics and are thus considered emerging or provisional diagnoses. ${ }^{1-3}$

In the olfactory cleft, REAH and SH often take on the herein described "crescent sign" morphology on sagittal images. Other- 


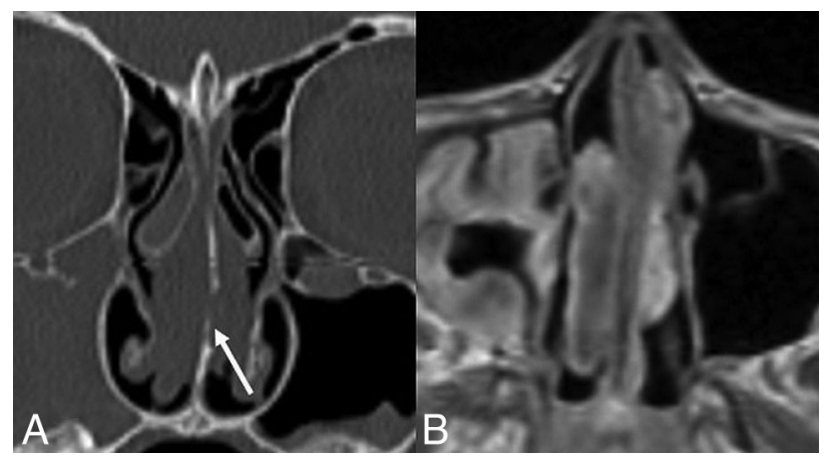

FIG 10. Chrondromesenchymal hamartoma. A, Coronal noncontrast $\mathrm{CT}$ in a pediatric patient shows polypoid soft tissue in the bilateral nasal cavities with mild erosive changes focally along the left margin of the nasal septum (white arrow). B, Axial Tl postcontrast, fat-saturated MR image demonstrates heterogeneous enhancement. No cystic or calcified components, frequently described in these lesions, are seen in this case. Images are courtesy of Dr Nafi Aygun, Johns Hopkins Hospital.

wise, these new and emerging entities have similar, locally destructive appearances on imaging. Certain entities have more typical features, such as calcifications with SMARCB1-deficient sinonasal carcinomas and cystic and calcified components in chondromesenchymal hamartomas, but no pathognomonic findings exist. These entities are rare, many exceedingly so, and should generally not be standard in a typical sinonasal mass differential. However, familiarity with these diagnoses is warranted. As more imaging examples of these entities are analyzed, further clarification of any specific imaging characteristics may be useful in refining these differentials.

\section{ACKNOWLEDGMENTS}

We would like to thank Dr Nafi Aygun, Johns Hopkins Hospital; Dr Caroline Robson, Boston Children's Hospital; Dr Christine Glastonbury, University of California, San Francisco; and Dr Margaret Brandwein-Weber, Mount Sinai Hospital, for providing excellent sample images.

\section{REFERENCES}

1. El-Naggar AK, Chan JKC, Grandis JR, et al, eds. WHO Classification of Head and Neck Tumours: WHO Classification of Tumours. Vol 9. 4th ed. Geneva: International Agency for Research on Cancer; 2017

2. Stelow EB, Bishop JA. Update from the 4th edition of the World Health Organization classification of head and neck tumours: tumors of the nasal cavity, paranasal sinuses and skull base. Head Neck Pathol 2017;11:3-15 CrossRef Medline

3. Bishop JA, Andreasen S, Hang JF, et al. HPV-related multiphenotypic sinonasal carcinoma: an expanded series of 49 cases of the tumor formerly known as HPV-related carcinoma with adenoid cystic carcinoma-like features. Am J Surg Pathol 2017;41:1690-701 CrossRef Medline

4. Thompson LD, Frachi A. New tumor entities in the 4 th edition of the World Health Organization classification of head and neck tumors: nasal cavity, paranasal sinuses and skull base. Virchows Arch 2018; 472:315-30. CrossRef Medline

5. Bishop AJ. Newly described tumor entities in the sinonasal tract pathology. Head Neck Pathol 2016;10:23-31 CrossRef Medline

6. Lewis JS Jr. Sinonasal squamous cell carcinoma: a review with emphasis on emerging histologic subtypes and the role of human papillomavirus. Head Neck Pathol 2016;10:60-67 CrossRef Medline

7. Bishop JA, Ogawa T, Stelow EB, et al. Human papillomavirus-re- lated carcinoma with adenoid cystic-like features: a peculiar variant of head and neck cancer restricted to the sinonasal tract. Am J Surg Pathol 2013;37:836-44 CrossRef Medline

8. Barnes L. Intestinal-type adenocarcinoma of the nasal cavity and paranasal sinuses. Am J Surg Pathol 1986;10:192-202 CrossRef Medline

9. Stelow EB, Jo VY, Mills SE, et al. A histologic and immunohistochemical study describing the diversity of tumors classified as sinonasal high-grade nonintestinal adenocarcinomas. Am J Surg Pathol 2011;35:971-80 CrossRef Medline

10. Leivo I. Sinonasal adenocarcinoma: update on classification, immunophenotype and molecular features. Head Neck Pathol 2016;10: 68-74 CrossRef Medline

11. Bishop JA, Antonescu CR, Westra WH. SMARCB1 (INI1)-deficient carcinomas of the sinonasal tract. Am J Surg Pathol 2014;38:1282-89 CrossRef Medline

12. Seol JG, Livolsi VA, O’Malley BW, et al. Respiratory epithelial adenomatoid hamartoma of the bilateral olfactory recesses: a neoplastic mimic? AJNR Am J Neuroradiol 2010;31:277-79 CrossRef Medline

13. Kossai M, El Zein S, Wassef M, et al. Olfactory epithelial hamartoma: a new subtype of sinonasal hamartoma. Am J Surg Pathol 2018;42: 9-17 CrossRef Medline

14. Wenig BM, Heffner DK. Respiratory epithelial adenomatoid hamartomas of the sinonasal tract and nasopharynx: a clinicopathologic study of 31 cases. Ann Otol Rhinol Laryngol 1995;104:639-45 CrossRef Medline

15. Huang YW, Kuo YJ, Ho CT, et al. Sinonasal seromucinous hamartoma. Eur Arch Otorhinolaryngol 2018;275:743-49 CrossRef Medline

16. Weinreb I, Gnepp DR, Laver NM, et al. Seromucinous hamartomas: a clinicopathological study of a sinonasal glandular lesion lacking myoepithelial cells. Histopathology 2009;54:205-13 CrossRef Medline

17. Tatekawa $\mathrm{H}$, Shimono $\mathrm{T}$, Ohsawa $\mathrm{M}$, et al. Imaging features of benign mass lesions in the nasal cavity and paranasal sinuses according to the 2017 WHO classification. Jpn J Radiol 2018;36:361-81 CrossRef Medline

18. Hawley KA, Ahmed M, Sindwani R. CT findings of sinonasal respiratory epithelial adenomatoid hamartomas: a closer look at the olfactory clefts. AJNR Am J Neuroradiol 2013;34:1086-90 CrossRef Medline

19. Jo VY, Mills SE, Cathro HP, et al. Low-grade sinonasal adenocarcinomas: the association with and distinction from respiratory epithelial adenomatoid hamartomas and other glandular lesions. Am J Surg Pathol 2009;33:401-08 CrossRef Medline

20. Fleming KE, Perez-Ordoñez B, Nasser JG, et al. Sinonasal seromucinous hamartoma: a review of the literature and a case report with focal myoepithelial cells. Head Neck Pathol 2012;6:395-99 CrossRef Medline

21. Seol JG, Livolsi VA, O’Malley BW Jr, et al. Respiratory epithelial adenomatoid hamartoma of the bilateral olfactory recesses: a neoplastic mimic? AJNR Am J Neuroradiol 2010; 31:277-79 CrossRef Medline

22. Hoxworth JM, Glastonbury CM, Fischbein NJ, et al. Focal opacification of the olfactory recess on sinus CT: just an incidental finding? AJNR Am J Neuroradiol 2008;29:895-97 CrossRef Medline

23. French CA. The importance of diagnosing NUT midline carcinoma. Head Neck Pathol 2013;7:11-16 CrossRef Medline

24. Stelow EB. A review of NUT midline carcinoma. Head Neck Pathol 2011;5:31-35 CrossRef Medline

25. Bauer DE, Mitchell CM, Strait KM, et al. Clinicopathologic features and long-term outcomes of NUT midline carcinoma. Clin Cancer Res 2012;18:5773-79 CrossRef Medline

26. Bishop JA, Westra WH. NUT midline carcinomas of the sinonasal tract. Am J Surg Pathol 2012;36:1216-21 CrossRef Medline

27. Bellizzi AM, Bruzzi C, French CA, et al. The cytologic features of NUT midline carcinoma. Cancer 2009;117:508-15 Medline

28. French CA, Ramirez CL, Kolmakova J, et al. BRD-NUT oncoproteins: a family of closely related nuclear proteins that block 
epithelial differentiation and maintain the growth of carcinoma cells. Oncogene 2008;27:2237-42 CrossRef Medline

29. Chau NG, Hurqitz S, Mitchell CM, et al. Intensive treatment and survival outcomes in NUT midline carcinoma of the head and neck. Cancer 2016;122:3632-40 CrossRef Medline

30. Kakkar A, Anotony VM, Irugu DV, et al. NUT midline carcinoma: a series of five cases, including one with unusual clinical course. Head Neck Pathol 2018;12:230 -36 CrossRef Medline

31. Bair RJ, Chick JF, Chauhan NR, et al. Demystifying NUT midline carcinoma: radiologic and pathologic correlations of an aggressive malignancy. AJR Am J Roentgenol 2014;203:W391-99 CrossRef Medline

32. Edgar M, Caruso AM, Kim E, et al. NUT midline carcinoma of the nasal cavity. Head Neck Pathol 2017;11:389-92 CrossRef Medline

33. Shaikh F, Pagedar N, Awan O, et al. Sinonasal NUT-midline carcinoma: a multimodality approach to diagnosis, staging, and post-surgical restaging. Cuereus 2015;7:e288 CrossRef Medline

34. Lewis JT, Oliveira AM, Nascimento AG, et al. Low-grade sinonasal sarcoma and neural and myogenic features: a clinicopathologic analysis of 28 cases. Am J Surg Pathol 2012;36:517-25 CrossRef Medline

35. Hellquist HB, Lungren J. Neurogenic sarcoma of the sinonasal tract. J Laryngol Otol 1991;105:186-90 CrossRef Medline

36. Wang X, Bledsoe KL, Graham RP, et al. Recurrent PAX3-MAML3 fusion in biphenotypic sinonasal sarcoma. Nat Genet 2014;46: 666-68 CrossRef Medline

37. Wong WJ, Lauria A, Hornick JL, et al. Alternate PAX3-FOXO1 oncogenic fusion in biphenotypic sinonasal sarcoma. Genes Chromosomes Cancer 2016;55:25-29 CrossRef Medline

38. Cannon RB, Wiggins RH 3rd, Witt BL, et al. Imaging and outcomes for a new entity: low-grade sinonasal sarcoma with neural and myogenic features. J Neurol Surg Rep 2017;78:e15-19 CrossRef Medline

39. Rooper LM, Huang SC, Antonescu CR, et al. Biphenotypic sinonasal sarcoma: an expanded immunoprofile including consistent nuclear $\boldsymbol{\beta}$-catenin positivity and absence of SOX10 expression. Hum Pathol 2016;55:44-50 CrossRef Medline

40. Lin Y, Liao B, Han A. Biphenotypic sinonasal sarcoma with diffuse infiltration and intracranial extension: a case report. Int J Clin Exp Pathol 2017;10:11743-46

41. Larque $A B$, Hakim S, Ordi J, et al. High-risk human papillomavirus is transcriptionally active in a subset of sinonasal squamous cell carcinomas. Mod Pathol 2014;27:343-51 CrossRef Medline

42. Alos L, Moyano S, Nadal A, et al. Human papillomaviruses are identified in a subgroup of sinonasal squamous cell carcinomas with favorable outcomes. Cancer 2009;115:2701-09 CrossRef Medline

43. Ruangritchankul K, Jitpasutham T, Kitkumthorn N, et al. Human papillomavirus-related multiphenotypic sinonasal carcinoma: first case report associated with intermediate-risk HPV type and literatures review. Hum Pathol: Case Reports 2018;14:20-24 CrossRef

44. Biegel JA, Zhou JY, Rorke LB, et al. Germ-line and acquired mutations of INI1 in atypical teratoid and rhabdoid tumors. Cancer Res 1999;59:74-79 Medline

45. Modena P, Lualdi E. Facchinette F, et al. SMARCB1/INI1 tumor suppressor gene is frequently inactivated in epithelioid sarcomas. Cancer Res 2005;65:4012-19 CrossRef Medline
46. Hornick JL, Dal Cin P, Fletcher CD. Loss of INI1 expression is characteristic of both conventional and proximal-type epithelioid sarcoma. Am J Surg Pathol 2009;33:542-50 CrossRef Medline

47. Agaimy A, Koch M, Lell M, et al. SMARCB1(INI1)-deficient sinonasal basaloid carcinoma: a novel member of the expanding family of SMARCB1-deficient neoplasms. Am J Surg Pathol 2014;38:1274-81 CrossRef Medline

48. Bell D, Hanna EY, Agaimy A, et al. Reappraisal of sinonasal undifferentiated carcinoma: SMARCB1 (INI1)-deficient sinonasal carcinoma-a single-institution experience. Virchows Arch 2015;467: 649-56 CrossRef Medline

49. Shatzkes DR, Ginsberg LE, Wong M, et al. Imaging appearance of SMARCB1 (INI1)-deficient sinonasal carcinoma: a newly described sinonasal malignancy. AJNR Am J Neuroradiol 2016;37:1925-29 CrossRef Medline

50. Zur KB, Branwein M, Wang B, et al. Primary description of a new entity, renal cell-like carcinoma of the nasal cavity: van Meergeren in the house of Vermeer. Arch Otolargyngol Head Neck Surg 2002;128: 441-47 CrossRef 11926922

51. Storck K, Hadi UM, Simpson R, et al. Sinonasal renal cell-like adenocarcinoma: a report on four patients. Head Neck Pathol 2008; 2:75-80 CrossRef Medline

52. Lee HM, Kang HJ, Lee SH. Metastatic renal cell carcinoma presenting as epistaxis. Eur Arch Otorhinolaryngol 2005;262:69-71 CrossRef Medline

53. Brandwein-Gensler M, Wei S. Envisioning the next WHO head and neck classification. Head Neck Pathol 2014;8:1-15 CrossRef Medline

54. Kim NI, Yang JI, Kim SS, et al. Sinonasal renal-cell like adenocarcinoma, a unique variant of primary clear cell carcinoma of the head and neck: the first reported case in Korea. Medicine 2017;96:e7711 CrossRef Medline

55. Zhenwei-Chen, Zhaoming-Wang, Hongqi-Shi, et al. Renal cell-like adenocarcinoma of the nasal cavity: a case report and review of the literature. Diag Pathol 2017;12:75 CrossRef Medline

56. Wu CN, Chuang IC, Chuang MJ, et al. Sinonasal renal cell-like adenocarcinoma: easily misdiagnosed sinonasal tumor. Head Neck 2018;40:e91-95 CrossRef Medline

57. Mason KA, Navaratnam A, Theodorakoploulo E, et al. Nasal chondromesenchymal hamartoma (NCMH): a systematic review of the literature with a new case report. J Otolargynol Head Neck Surg 2015; 44:28 CrossRef Medline

58. Stewart DR, Messinger Y, Williams GM, et al. Nasal chondromesenchymal hamartomas arise secondary to germline and somatic mutations of DICER 1 in the pleuropulmonary blastoma tumor predisposition disorder. Hum Genet 2014;133:1443-50 CrossRef Medline

59. Ozolek JA, Carrau R, Barnes EL, et al. Nasal chondromesenchymal hamartoma in older children and adults: series and immunohistochemical analysis. Arch Pathol Lab Med 2005;129:1444-50 Medline

60. Wang T, Li W, Xu X, et al. Nasal chondromesenchymal hamartoma in young children: $\mathrm{CT}$ and MRI findings and review of literature. World J Surg Oncol 2014;12:257 CrossRef Medline

61. Yao-Lee A, Ryan M, Rajaram V. Nasal chondromesenchymal hamartoma: correlation of typical MR, CT and pathological findings. Pediatr Radiol 2011;41:675-77 CrossRef Medline 